\title{
O processo de materialidade do núcleo politécnico comum no contexto do Ensino Médio Integrado no Instituto Federal de Santa Catarina, Campus Chapecó
}

\section{The materiality process of the common polytechnical core's in the context of Integrated High School at the Instituto Federal de Santa Catarina, Chapecó Campus}

\section{El proceso de materialidad del núcleo politécnico común en el contexto de la Enseñanza Secundaria Integrada del Instituto Federal de Santa Catarina, Campus Chapecó}

\author{
Belchior, Izac de Sousa ${ }^{1}$ (Uruçuí, PI, Brasil) \\ ORCID ID: https://orcid.org/0000-0001-5968-9998 \\ Silva, Adriano Larentes da² (Chapecó, SC, Brasil) \\ ORCID ID: https://orcid.org/0000-0002-3604-5281
}

\begin{abstract}
Resumo
Este artigo debate o processo de construção do núcleo politécnico comum no Ensino Médio Integrado (EMI) do Instituto Federal de Santa Catarina (IFSC), Campus Chapecó, a partir das contribuições de dois grupos de trabalho responsáveis pela reestruturação curricular do EMI nesse campus. Seu objetivo é mostrar os limites e possibilidades de materialização do núcleo politécnico comum, enquanto conceito filosófico, instrumento metodológico e práxis, no Ensino Médio Integrado. O trabalho está subdividido em três seções: a primeira trata do Ensino Médio Integrado e seus desafios, tendo em vista os esforços de superação da dualidade do ensino; a segunda descreve a problemática do núcleo politécnico comum como práxis da educação politécnica e aporte para uma formação humana omnilateral e a terceira aborda a tentativa de materialidade do núcleo politécnico comum na experiência do IFSC, Campus Chapecó, a partir das Oficinas de Integração e outras unidades curriculares interdisciplinares. Os dados e análises resultam de pesquisa bibliográfica, documental e de campo, realizadas de 2018 a 2020, junto ao IFSC, as quais evidenciaram os debates, embates e possibilidades de avanços de práticas docentes interdisciplinares e integradas, bem como de uma organização curricular coerente com a perspectiva de formação humana integral no contexto do ensino médio dos Institutos Federais.
\end{abstract}

Palavras-chave: Ensino Médio Integrado. Politecnia. Núcleo Politécnico Comum.

\begin{abstract}
This article debates about the common polytechnical core's development in the Integrated High School (EMI) at Instituto Federal de Santa Catarina (IFSC), Chapecó Campus, by the contributions from two workgroups that were responsible for the curricular reconstruction of EMI in that campus. It aims to show the limits and possibilities of materialization of the common polytechnical core, as a philosophical concept, a methodological tool and praxis, in the Integrated High School. This works is divided in three sections: the first deals with the Integrated High School and it's challenges, bearing in mind the efforts to overcome the duality of teaching; the second describes the common polytechnical core issue as a polytechnical education praxis and input to a omnilateral humanitarian education, and the third addresses the efforts to materialize the common polytechnical core in the IFSC's (Chapecó Campus) experience, through the Integration Workshops and other interdisciplinary curricular units. The data and analysis stem from bibliographical, document and field research, held from 2018 to 2020, along with IFSC, whom highlighted the debates, clashes and possibilities of advances in interdisciplinary and

${ }^{1}$ C. Professor do Instituto Federal de Educação, Ciência e Tecnologia do Piauí izac.belchior@ifpi.edu.br 2 Pró-reitor de ensino do IFSC. Professor do mestrado PROFEPT/IFSC. adriano.larentes@gmail.com


integrated teaching practices, and a coherent curricular organization with an integral humanitarian formation perspective, in the context of Federal Institutes' high school.

Keywords: Integrated High School. Polytechnical. Common Polytechnical Core.

\section{Resumen}

Este artículo debate el proceso de construcción del núcleo politécnico común en la Enseñanza Secundaria Integrada (EMI) del Instituto Federal de Santa Catarina (IFSC), Campus Chapecó, a partir de las contribuciones de dos grupos de trabajo responsables por la reestructuración curricular de la EMI en aquel campus. Está subdividido en tres secciones: la primera trata de la Enseñanza Secundaria Integrada y sus desafíos, teniendo en cuenta los esfuerzos de superación de la dualidad de enseñanza; la segunda, describe la problemática del núcleo politécnico común como praxis de la educación politécnica y aporte para una formación humana omnilateral; y la tercera, aborda el intento de materialidad del núcleo politécnico común en la experiencia del IFSC, Campus Chapecó, a partir de las Oficinas de Integración y otras unidades curriculares interdisciplinares. El objetivo de este artículo es mostrar los límites y posibilidades de materialización del núcleo politécnico común, como concepto filosófico, instrumento metodológico y praxis, en la Enseñanza Secundaria Integrada. Los datos y análisis resultan de investigación bibliográfica, documental y de campo, realizada de 2018 a 2020, junto al IFSC, las cuales mostraron los debates, embates y posibilidades de avances de prácticas docentes interdisciplinares e integradas y de uma organización curricular que busca ser coerente com la perspectiva de formación humana integral bajo el contexto de la enseñanza secundaria de los institutos federales.

Palabras-clave: Enseñanza Secundaria Integrada. Educación Politécnica. Núcleo Politécnico Común.

\section{Introdução}

O Ensino Médio Integrado (EMI) é a concretude dos debates realizados, no Brasil, por pesquisadores, trabalhadores do campo da Educação e demais lideranças civis interessadas numa proposta de educação pública, laica e emancipadora, a partir de meados dos anos 1980, ainda no processo de redemocratização. Tal concepção de ensino deve ser entendida como condição de superação da dualidade estrutural da educação, marcada historicamente pela cisão entre educação propedêutica, direcionada aos filhos das classes dirigentes, e o ensino profissionalizante, voltado à classe trabalhadora e, consequentemente, a seus filhos. Esse modelo educacional dual é, manifestadamente, desigual e injusto, pois contribui para a manutenção da estrutura das contradições da sociedade brasileira ${ }^{3}$.

A busca pela superação da dualidade educacional foi iniciada, em parte, com a publicação do Decreto $n^{0} 5.154 / 2004$, no primeiro governo do ex-presidente

${ }^{3}$ Considera-se que a superação da dualidade educacional não é uma tarefa restrita à ação da escola, mas que dela também depende. 
Luiz Inácio Lula da Silva, do Partido dos Trabalhadores, que possibilitou a junção e o equilíbrio entre o ensino médio e a educação profissional na forma integrada, constituindo, assim, o Ensino Médio Integrado. Essa forma de oferta não corresponde apenas à integração de duas modalidades de ensino distintas, mas também e, em essência, à tradição da busca por uma formação humana omnilateral ${ }^{4}$. Tal concepção e forma de oferta têm sido seriamente ameaçadas, sobretudo pela Lei no ${ }^{0} 13.415 / 2017$, que trata do chamado "Novo Ensino Médio", e pela aprovação da Emenda Constitucional 95, que congela os gastos públicos por vinte anos, além de outros recentes ataques.

O EMI é marcado pelo desafio de formar a juventude brasileira, tendo o trabalho como princípio educativo, numa perspectiva politécnica ${ }^{5}$ e de base humanística, voltada à formação de sujeitos sociais engajados com a transformação social. Desse modo, o currículo proposto por essa concepção de ensino deve conduzir o estudante a perceber a realidade atual como ponto de partida e a realidade transformada como ponto de chegada. Inseridos nessa visão, os estudantes devem conhecer e combater as mais diversas formas de dominação do modo de produção capitalista que promovem a alienação ${ }^{6}$ e o estranhamento ${ }^{7}$ do seu trabalho e do produto resultante dessa ação.

No contexto da educação profissional brasileira, a estrutura curricular do EMI é formada por, pelo menos, três núcleos: o técnico, responsável por agregar os componentes curriculares e profissionais da área específica/técnica do curso

\footnotetext{
${ }^{4}$ Conforme mostra Sousa Júnior (2009, p. 284), "o conceito de omnilateralidade é de grande importância para a reflexão em torno do problema da educação em Marx. Ele se refere a uma formação humana oposta à formação unilateral provocada pelo trabalho alienado, pela divisão social do trabalho, pela reificação, pelas relações burguesas estranhadas". Segundo esse mesmo autor, tal conceito guarda muitas relações com o conceito de politecnia, mas não é sinônimo desse. De acordo com Sousa Júnior (2009, p. 287-288), "o elemento fundamental de distinção entre os dois conceitos é justamente o fato de que a politecnia representa uma proposta de formação aplicável no âmbito das relações burguesas, articulada ao próprio momento do trabalho abstrato, ao passo que a omnilateralidade apenas se faz possível no conjunto de novas relações, no 'reino da liberdade'."

${ }^{5} \mathrm{O}$ conceito de politecnia aqui utilizado tem como referência principalmente as publicações de Saviani (2003, e 2007). Porém, considera também as contribuições e ponderações de Nosella (2007), ao apontar as "contradições" e/ou "desconforto" no que tange à filologia, semântica, história e perspectiva política desse conceito e seus usos no contexto atual, bem como as abordagens sobre a politecnia advindas de autores anarquistas, como Proudhon.

${ }^{6}$ Esse conceito é desenvolvido por Marx, ao entender que, no modo de produção capitalista, o movimento do trabalho produz um objeto que não mais pertence ao ser humano que o produziu, isto é, que dele se alienou. Desse modo, "a 'perda do objeto e a servidão ao objeto' é o fator imediatamente perceptível do processo de alienação do trabalho [...]" (ANTUNES, 2012, p. 31).

7 Conceito que guarda uma relação direta com a subjetividade do trabalho alienado, pois, no modo de produção capitalista, "o trabalhador não se reconhece naquilo que é o objeto do seu trabalho - isso decorre do fato do ser humano já não se reconhecer no ato da produção" (ANTUNES, 2012, p. 32). 
oferecido; o de formação básica, que agrupa os componentes curriculares considerados propedêuticos, com seus respectivos licenciados; e o núcleo politécnico comum, que concilia, de maneira integrada, interdisciplinar e dialógica, os conhecimentos curriculares e profissionais dos núcleos anteriores.

O conceito e a concepção de núcleo politécnico comum ganharam força a partir de 2008, quando se deram os debates acerca do Catálogo Nacional de Cursos Técnicos de Nível Médio (CNCT), e foram incorporados em 2012, pelas Diretrizes Curriculares Nacionais para a Educação Profissional Técnica de Nível Médio. De acordo com essas diretrizes, há uma estreita relação entre o núcleo politécnico comum e a organização dos cursos mediante eixos tecnológicos, visando à uma formação integral, que permita a compreensão dos diferentes fundamentos que alicerçam as tecnologias e o sistema produtivo atual (BRASIL, 2012).

Dessa maneira, pensar em núcleo politécnico comum requer um exercício no qual, primeiramente, é preciso despir-se do sentido equivocado da palavra "politécnico", como agrupamento de várias ciências, e caminhar para o sentido dado, por exemplo, por Saviani (2007, p. 162), para quem "[...] o conceito de politecnia implica a união entre escola e trabalho ou, mais especificamente, entre instrução intelectual e trabalho produtivo"; e por Ramos (2008, p. 3), que considera "politecnia" "uma educação que possibilita a compreensão dos princípios científico-tecnológicos e históricos da produção moderna, de modo a orientar os estudantes à realização de múltiplas escolhas".

Pautado na defesa de uma educação politécnica de base unitária humanística para o ensino médio, o presente artigo objetiva mostrar os limites e possibilidades de materialização do núcleo politécnico comum, enquanto conceito filosófico, instrumento metodológico e práxis, no contexto do Ensino Médio Integrado do Instituto Federal de Santa Catarina (IFSC), Campus Chapecó. O texto é um recorte da dissertação de mestrado, defendida em 2020, junto ao Programa de PósGraduação em Educação Profissional e Tecnológica (PROFEPT/IFSC). Entre os dados analisados na referida dissertação, está um conjunto de documentos produzidos por dois Grupos de Trabalho (GTs), designados pela direção do IFSC, Campus Chapecó, para construir novas possibilidades para a organização do Ensino 
Médio Integrado nesse campus. As diferentes reuniões dos grupos foram acompanhadas e sistematizadas entre março e dezembro de 2019, a partir de uma abordagem qualitativa e embasada no método histórico-dialético, visando situar a experiência analisada no contexto histórico e material da educação profissional, dos Institutos Federais e do Ensino Médio Integrado no Brasil. Foi com base nos materiais coletados, e em um conjunto de publicações sobre o EMI e o núcleo politécnico comum, que este texto foi construído.

É importante salientar que o processo de materialidade do núcleo politécnico comum no currículo do EMI é desafiador, pois a promoção de práticas docentes integradas e interdisciplinares requer planejamento sistemático, além de romper com a tradição acadêmica do conhecimento disciplinar. Conhecer o trabalho e os esforços empreendidos por professores, servidores técnico-administrativos e estudantes é, portanto, uma forma de mostrar a práxis pedagógica ${ }^{8}$ do EMI, a partir de uma realidade concreta. Sua observação possibilitou o registro dos esforços desses grupos para avançar nos debates a respeito da construção de um núcleo politécnico comum mais ousado, que permitisse um diálogo estreito entre cursos técnicos integrados de eixos tecnológicos distintos, ou seja, a ascensão de um Ensino Médio Integrado, no mais absoluto sentido do termo.

\section{O Ensino Médio Integrado e seus desafios}

O Ensino Médio Integrado é resultado da revogação do Decreto $\mathrm{n}^{\circ}$ 2.208/1997 pelo Decreto $n^{\circ} 5.154 / 2004$, que permite a integração do ensino médio à educação profissional, na forma integrada. Essa integração é uma reivindicação antiga de vários profissionais e pesquisadores do campo da Educação, e sua oferta é discutida, pelo menos, desde os anos 1980, mais marcadamente com o fim da ditadura militar e a instalação do Congresso Nacional Constituinte, em 1987 (RAMOS, 2010). Essa forma de oferta tem como pressuposto a superação da dualidade,

\footnotetext{
${ }^{8}$ Segundo Caldeira e Zaidan (2013, p. 21): "Nessa perspectiva, a atividade do professor é práxis quando é feita tendo em vista o alcance de determinados resultados. Essa antecipação consciente do resultado que se pretende atingir é de natureza teórica. Mas, para que a realidade seja transformada, é necessária uma ação prática. Por sua vez, as necessidades práticas, que emergem do cotidiano da sala de aula e de outros espaços escolares, demandam uma teoria. Portanto, na prática estão presentes a ideia e a ação, que buscam transformar a realidade, ou seja, há uma unidade entre teoria e prática, entre concepção e ação" (SÁNCHEZ VÁZQUEZ, 1977 apud CALDEIRA; ZAIDAN, 2013, p. 21). 
historicamente materializada na sociedade brasileira, entre trabalho intelectual e trabalho manual, ou seja, uma superação da visão da educação profissional como preparação para o trabalho, assim como um ensino médio voltado apenas para o ingresso nos cursos de graduação. Para Moura (2007, p. 5), "a relação entre a educação básica e profissional no Brasil está marcada historicamente pela dualidade". Com o Ensino Médio Integrado, a busca pela superação dessa dualidade foi posta como um desafio a ser enfrentado.

Para uma melhor compreensão do EMI, Ciavatta (2012, p. 84) destaca que, no caso da formação integrada ou do ensino médio integrado ao ensino técnico, "queremos que a educação geral se torne parte inseparável para o trabalho". O trabalho ao qual a autora se refere diz respeito às suas mais variadas formas, não apenas restrito ao trabalho assalariado, pois o Ensino Médio Integrado deve garantir uma formação completa, marcada pela concepção de educação politécnica e unitária. Tal concepção dialoga diretamente com os escritos de Gramsci (1982) sobre a defesa de uma escola unitária para os trabalhadores. Segundo esse autor, caberia à escola unitária "se propor a tarefa de inserir os jovens na atividade social, depois de tê-los levado a um certo grau de maturidade e capacidade, à criação intelectual e prática e a uma certa autonomia na orientação e na iniciativa" (GRAMSCI, 1982, p. 121). Esse desafio, no entanto, implicava, de acordo com Gramsci (1989), em investimentos públicos, na garantia de condições de trabalho docente, na existência de condições estruturais necessárias, no rompimento com a dicotomia entre trabalho manual e intelectual e com os modelos de ensino puramente dogmáticos e mecânicos. Conforme mostraram Silva e Nosella (2019), com essa perspectiva, Gramsci idealizava uma escola que fosse de "elevada cultura para todos", uma "cultura extrema", viva, que permitiria aos trabalhadores o alcance da hegemonia.

Pautado na perspectiva de Gramsci, o EMI, enquanto condição para uma educação politécnica de base unitária humanística, deve garantir, aos seus sujeitos, "a compreensão dos princípios científico-tecnológicos e históricos da produção moderna, de modo a orientar os estudantes à realização de múltiplas escolhas" (RAMOS, 2008, p. 3). Como condição para uma educação unitária, deve proporcionar "que todos tenham acesso aos conhecimentos, à cultura e às mediações necessárias 
para trabalhar e para produzir a existência e a riqueza social" (RAMOS, 2008, p. 2). Assim, o ensino médio na forma integrada se propõe a romper com a fragmentação do conhecimento, adestramento, dualismo, pragmatismo, pedagogia das competências e a chamada teoria do capital humano. Pressupõe um tipo de formação que "preconiza a integração de todas as dimensões da vida - o trabalho, a ciência e cultura" (CIAVATTA; RAMOS, 2011, p. 31), ou seja, uma formação que desenvolve "a compreensão das relações sociais de produção e do processo histórico e contraditório de desenvolvimento das forças produtivas" (CIAVATTA; RAMOS, 2011, p. 31). A compreensão dessas relações sociais de produção é necessária para que a classe trabalhadora transgrida a lógica do modo de produção capitalista de estranhamento e alienação do trabalho.

De acordo com Saviani (2003), a dimensão do trabalho como princípio educativo aparece no currículo ${ }^{9}$ do ensino fundamental de forma implícita, e a escola não precisa fazer referência direta ao processo de trabalho. Já no ensino médio, o currículo organiza a questão do trabalho de maneira explícita, mostrando ao aluno o modo como o trabalho está organizado e se desenvolve na sociedade moderna. Ramos (2008) esclarece que o trabalho como princípio educativo não se confunde com o "aprender fazendo", e nem com formar apenas para o trabalho simples, pois o homem é produtor da sua realidade e poderá, assim, transformá-la ${ }^{10}$.

Nessa perspectiva, observa-se que a práxis pedagógica não deve simplesmente privilegiar aspectos mais teóricos ou mais práticos das vivências do educando ou componentes do currículo da base técnica ou da comum. Ao tratar da indissociabilidade sobre teoria e prática, Araújo e Frigotto (2015) mostram que a didática, numa perspectiva do EMI, deve ser tratada como uma unidade indissolúvel, numa relação de autonomia e dependência de um termo em relação a outro. Assim,

\footnotetext{
${ }^{9}$ Para Thiesen (2013), "o currículo não pode existir fora da realidade concreta, na qual homens e mulheres tecem e engendram os elementos de sua constituição histórica, seja na ação mesma da atividade educativa, seja nas formulações teóricas produzidas sobre essa ação. A produção do currículo, como campo de lutas, engendra-se no contexto tensionado das relações sociais mediatizadas pelos interesses de classe e materializadas na atividade educativa como um jogo de forças em torno do seu objeto mais precioso - o conhecimento" (THIESEN, 2013, p. 593).

${ }^{10}$ Segundo Ciavatta (2009), a introdução do trabalho como princípio educativo na atividade escolar ou na formação de profissionais, "supõe recuperar para todos a dimensão do conhecimento científico-tecnológico da escola unitária e politécnica, introduzir nos currículos a crítica histórico-social do trabalho no sistema capitalista, os direitos do trabalho e o sentido das lutas históricas no trabalho, na saúde e na educação".
} 
não se deve valorizar a teoria em detrimento da prática, e vice-versa. Essa perspectiva de unidade em relação à teoria e prática é que precisa orientar os projetos de ensino integrado. Além disso, a categoria da historicidade deve estar sempre presente no contexto do EMI, enfatizando os seres humanos como seres histórico-sociais, capazes de mudar a realidade, como destaca Moura (2007). Nesse sentido, Araújo e Frigotto $(2015$, p. 69) apontam que "o compromisso com a transformação social revela a teleologia do projeto de ensino integrado. É esse o princípio que distingue a práxis marxista da filosofia pragmática [...]". Portanto, o EMI deve adotar, no seu currículo e na prática docente, ações coerentes, que possibilitem aos sujeitos uma educação emancipadora e transformadora da realidade social, econômica e ambiental.

O currículo no EMI tem como ponto de partida uma construção coletiva, participativa e democrática com a sociedade e o mundo do trabalho, bem como a sua constante avaliação e reavaliação, numa perspectiva dialética, partindo do pressuposto que o currículo deve ser pensado e construído como algo dinâmico, pois assim são os grupos sociais, o trabalho, os valores e a cultura.

A construção do currículo integrado é, necessariamente, um ato coletivo, que requer o planejamento conjunto das ações, com metodologia e objetivos claros. Para ser construído, o currículo integrado exige que a escola seja, de fato, um espaço democrático e participativo. Se não for assim, grande parte dos esforços empreendidos podem não resultar na efetivação do currículo integrado no cotidiano da sala de aula (SILVA, 2014, p. 22-23).

O currículo integrado é a voz dos mais diversos atores que compõem a sociedade e o mundo do trabalho. Pensar sobre ele requer, sobretudo, que os envolvidos nos processos educativos, isto é, docentes, discentes, família e comunidade acreditem na concretude do que está sendo pensado e será posto em prática. Para tanto, busca-se imprimir, nos currículos integrados, percursos ou itinerários formativos que sustentem o trabalho e a educação para além do capital, bem como um planejamento educacional ${ }^{11}$ que permita aos docentes superar a fragmentação do conhecimento.

11 O planejamento é entendido aqui na perspectiva de Vasconcellos (2009) e Gandin (2008). Para eles, o planejamento educacional implica uma enorme complexidade, pois o que está em pauta é a formação do ser humano a partir de um movimento individual e coletivo, que requer intencionalidade, objetivos claros e conexão 
O Ensino Médio Integrado, segundo Moura (2007), está organizado por conhecimentos científicos e tecnológicos, articulados em quatro núcleos que interagem permanentemente. São eles: 1) um núcleo comum, que integra disciplinas das quatro áreas do conhecimento do ensino médio; 2) uma parte diversificada, que integra disciplinas voltadas para uma maior compreensão das relações existentes no mundo do trabalho e para uma articulação entre esse e os conhecimentos acadêmicos; 3) formação profissional, que integra disciplinas específicas de cada curso; 4) prática profissional. Para esse autor, tal forma de organização serve para fins meramente didáticos e explicativos e, na prática, "[...] os núcleos estão interrelacionados e em constante diálogo proporcionado pelo desenvolvimento de projetos interdisciplinares ou outras metodologias que permitam o diálogo entre outras disciplinas que os compõem (MOURA, 2007, p. 27).

A interdisciplinaridade e a contextualização também são pressupostos que permeiam o EMI, no que diz respeito à forma de organização do trabalho pedagógico. Para Moura (2007, p. 24), esses pressupostos correspondem a "uma mudança de atitude que se expressa quando o indivíduo analisa um objeto a partir do conhecimento das diferentes disciplinas, sem perder de vista método, objetivos e autonomia próprios de cada disciplina". Thiesen (2013, p. 593) percebe a interdisciplinaridade como "um princípio mais de natureza epistemológica do que metodológica ou didática, situada, portanto, no campo da racionalidade humana em que se derivam formas de compreensão sobre a materialidade histórica". Sobre a contextualização, Araújo e Frigotto (2015, p. 69) destacam a importância de uma "íntima" articulação dos conteúdos formativos com a realidade social e com os projetos políticos dos trabalhadores e de suas organizações sociais. A interdisciplinaridade e a contextualização permitem aos estudantes outro olhar ou múltiplos olhares acerca dos conteúdos trabalhados na escola.

Entre os grandes desafios encontrados no ensino integrado estão a operacionalização curricular, a organização dos sistemas de ensino e os problemas de ordem conceitual (ARAÚJO; FRIGOTTO, 2015). Muitas vezes, "o ensino integrado tem sido compreendido apenas como estratégia de organização dos conteúdos

com o contexto social mais amplo, com o projeto político-pedagógico da escola, com a democracia e com condições efetivas para a participação de todos. 
escolares, sem revelar o conteúdo ético-político transformador da proposta ou materialidade de sua operacionalização" (ARAÚJO; FRIGOTTO, 2015, p. 65). Outro obstáculo a ser superado é a materialização do núcleo politécnico comum no contexto do EMI, pois é a partir desse núcleo, pensado numa perspectiva politécnica de base unitária $^{12}$ humanística, que se observam inúmeras possibilidades de desenvolver práticas pedagógicas proativas no referido contexto.

\section{A problemática do núcleo politécnico comum}

A educação politécnica, apesar de estar fortemente associada às concepções de Marx sobre a análise da superação das condições materiais de trabalho nas fábricas inglesas do século XIX, também tem relação direta com o pensamento socialista anarquista, de maneira mais assentada nas bases conceituais propostas por Pierre-Joseph Proudhon. No que tange à politecnia, a indissociabilidade entre formação mental, física e instrução tecnológica, proposta por Marx, não diverge da teoria educacional anarquista, na qual a questão da politecnia encontra-se agrupada nas dimensões física, intelectual e moral, entendendo a primeira como aspecto físico, propriamente dito, e a educação manual ou profissional; a segunda consistia na apreensão de toda carga cultural produzida pela humanidade; e a terceira estava baseada no aprendizado através da prática da solidariedade e na construção comunitária da liberdade (GALLO, 1993, p. 35).

Ao analisar os escritos de Proudhon, Gallo (1993) destaca dois termos centrais: o primeiro é a democracia do acesso ao ensino, através da justiça na igualdade de oportunidade, para que a educação abranja toda a sociedade, tendo a autogestão como direção na organização da educação; o segundo termo central tem o trabalho como principal instrumento de aprendizagem e como proposta de educação politécnica, em que a generalidade deve preceder a especialização. Gallo (1993), ao tratar da questão do trabalho proposta por Proudhon, afirma que ele enfatiza o domínio de todas as etapas do processo produtivo pelo trabalhador, das estratégias de produção até a fabricação do objeto proposto. Desse modo, ocorre a superação da

\footnotetext{
12 Segundo Moura, Lima Filho e Ramos (2015), as concepções de escola unitária, de Gramsci, e de politecnia, proveniente de Marx e de Engels, não colidem. Ao contrário, são complementares. Gramsci aprofunda um aspecto da politecnia não muito explorado por Marx e Engels: sua dimensão intelectual, cultural e humanística. 
alienação, a partir da aprendizagem politécnica, que deveria ocorrer numa oficina escola, onde a aplicação prática do conhecimento teórico seria imediata, de modo que a partir do prático pudesse se chegar à formulação e ao entendimento dos novos conceitos teóricos. Desta maneira, "a politecnia pressupõe naturalmente a pluralidade, a percepção e a compreensão do múltiplo, não como dividida, mas como uma complexidade articulada e interdependente" (GALLO, 1993, p. 37).

Para pesquisadores contemporâneos como Saviani (2003), em se tratando da temática supracitada, deve-se fazer uma distinção entre o termo politecnia e o conceito de domínio das diferentes técnicas fragmentadas, isto é, de um trabalho com caráter polivalente, como, de igual modo, de um trabalhador adestrado para o mercado de trabalho - numa visão eufemística do termo, um trabalhador qualificado. A gênese da politecnia está no domínio dos fundamentos do trabalho produtivo moderno, que se baseia na ciência; sobre essa estrutura é que o trabalhador precisa dominar. A partir do domínio dos fundamentos científicos, o trabalhador estará apto a desenvolver outras atividades laborais do trabalho moderno. De acordo com Saviani (2003, p. 140), "[...] trata-se de propiciar-Ihe um desenvolvimento multilateral, um desenvolvimento que abarca todos os ângulos da prática produtiva na medida em que ele domina aqueles princípios que estão na base da organização da produção moderna". Ele esclarece que, "Na sociedade capitalista, a ciência é incorporada ao trabalho produtivo, convertendo-se em potência material. O conhecimento se converte em força produtiva e, portanto, em meio de produção" (SAVIANI, 2003, p. 13).

É a partir da concepção de educação politécnica que se desenvolve o conceito de núcleo politécnico comum como elemento agregador de práticas docentes integradas e interdisciplinares, responsáveis pela relação dialógica entre o núcleo comum e o núcleo técnico da estrutura curricular dos cursos do EMI. O núcleo politécnico comum surge com o Parecer $n^{\circ} 11$, aprovado em 12 de junho de 2008, que institui o CNCT, justificado pela quantidade excessiva de nomenclaturas e cursos técnicos de nível médio, além de "[...] uma dispersão de títulos, dificuldade na orientação e informação ao usuário e à sociedade, bem como para a formulação de políticas, planejamento e avaliação dessa modalidade de educação profissional" (BRASIL, 2008, p. 1). 
A criação do CNCT, de igual modo, fundamenta-se, segundo o referido parecer, na promoção do processo nacional de avaliação da educação profissional técnica, na organização em função da organização sócio-ocupacional e tecnológica, no mapeamento da oferta da Educação Profissional Técnica de Nível Médio, bem como na correção de distorções e subsídios para formulações de políticas públicas (BRASIL, 2008). No mesmo documento, também se ressaltou a necessidade de implantação da classificação em eixos tecnológicos, assim como os cursos de graduação tecnológica, face aos novos cenários científicos de construção de competências similares dos novos sistemas produtivos, novos métodos e novas concepções educacionais. Para Machado (2010, p. 93), o CNCT “[...] trouxe a ideia de um núcleo politécnico comum para cada eixo tecnológico, justificada para tornar o processo educativo mais sintonizado". Esse núcleo, segundo a autora, integra a estrutura curricular dos citados eixos tecnológicos. O debate em relação ao CNCT e aos eixos tecnológicos serviu de base para formulações posteriores sobre o núcleo politécnico comum e, em especial, para a definição das Diretrizes Curriculares Nacionais para a Educação Profissional Técnica de Nível Médio, de 2012. Em seu Capítulo II, Art. 13, § II, as DCNs/EPTNM esclarecem que estruturar cursos dessa modalidade, orientados por eixos tecnológicos, implica considerar:

(...) o núcleo politécnico comum correspondente a cada eixo tecnológico em que se situa o curso, que compreende os fundamentos científicos, sociais, organizacionais, econômicos, políticos, culturais, ambientais, estéticos e éticos que alicerçam as tecnologias e a contextualização do mesmo no sistema de produção social (BRASIL, 2012, p. 4).

Cabe destacar que o núcleo politécnico comum, segundo Machado (2010), favorece a introdução de projetos pedagógicos integradores, tanto no conteúdo como em outras aprendizagens, uma formação do aluno que proporciona o desenvolvimento de sentido crítico, a compreensão da cultura tecnológica, a criatividade e a comunicação de ideias. No que diz respeito ao núcleo politécnico comum na prática curricular, pode-se observar que:

A noção de núcleo politécnico comum foi introduzida pela legislação sobre eixo tecnológico com a perspectiva de ser um componente curricular transversal, e não uma disciplina, o que significa dizer que os conteúdos desse núcleo também podem ser interpretados na sua função de eixo estruturador (MACHADO, 2010, p. 103). 
Para Sobrinho (2017), há uma relação direta, uma conexão entre o núcleo politécnico comum e as práticas profissionais integradas.

\begin{abstract}
A Prática Profissional Integrada, na organização curricular em núcleos, é parte essencial do Núcleo Politécnico, o qual é espaço onde se garantem, concretamente, conteúdos, formas e métodos responsáveis por promover, durante todo o itinerários formativos, a politecnia, a formação integral e omnilateral e a interdisciplinaridade (SOBRINHO, 2017, p. 131).
\end{abstract}

O núcleo politécnico comum pode garantir a superação de grandes desafios do EMI, que consistem no avanço de práticas docentes que busquem afastar a fragmentação do conhecimento; a dualidade entre teoria e prática; a valorização do conhecimento técnico em detrimento do propedêutico e vice-versa. Sua superação deve vir mediante um currículo que garanta formas integradas e interdisciplinares de promoção do conhecimento. Dessa forma, o núcleo politécnico comum pode responder a essas demandas, pois contribui para estruturar, de forma interdisciplinar, integrada e transversal, a oferta da educação básica e profissional durante toda a duração do EMI.

Apresenta-se, a seguir, o contexto da experiência do Instituto Federal de Santa Catarina, campus Chapecó, bem como os esforços empreendidos para materialização do núcleo politécnico comum no EMI nessa instituição de ensino.

\title{
4 A busca pela materialidade do núcleo politécnico comum no Ensino Médio Integrado no Instituto Federal de Santa Catarina, Campus Chapecó
}

A fim de exemplificar o movimento que focalizou a materialidade do núcleo politécnico comum no contexto da Rede Federal de Educação Profissional e Tecnológica, toma-se como referência a experiência do IFSC, campus Chapecó. As análises aqui apresentadas têm como referência as pesquisas realizadas nesse campus, em 2019, as quais resultaram na dissertação anteriormente citada e, mais especificamente, no produto educacional intitulado Caderno de Memórias: Debates, Proposições e Tensões no Processo de Construção de Currículos Integrados no Instituto Federal de Santa Catarina, Campus Chapecó. Esse produto (encartado à dissertação) sintetizou os debates realizados entre março e dezembro de 2019, pelos GTs designados para a reformulação do Curso Técnico de Nível Médio Integrado em 
Informática e a implantação do Curso Técnico Integrado em Sistemas de Energia Renovável. A pesquisa foi do tipo misto (observação não-participante e pesquisa documental), de natureza aplicada, pautada em uma abordagem qualitativa. As reuniões dos GTs foram registradas em atas do curso de Informática, no formato de fotografias, gravações em áudio e registros escritos feitos pelos pesquisadores e demais participantes. Os áudios foram, posteriormente, transcritos e utilizados com a autorização dos participantes, mediante a assinatura do Termo de Consentimento Livre e Esclarecido (TCLE). Os dois GTs eram compostos por mais de 20 servidores, sendo, a maioria, docente da EBTT ${ }^{13}$; contando também com representantes da Coordenadoria Pedagógica e Grêmio Estudantil do Campus Chapecó. A partir dos debates e tensões que ocorriam nas reuniões de socialização dos grupos, foram registradas as proposições de construção do currículo integrado e a construção da materialização do núcleo politécnico comum.

Para compreender a dinâmica de busca da materialidade do núcleo politécnico comum no IFSC, Campus Chapecó, é importante inteirar-se de que os desafios tiveram início em 2008, com os debates para a implantação do curso integrado (Proeja) para jovens e adultos na área de eletromecânica, e que continuaram em 2010, com a construção do projeto do Curso Técnico de Nível Médio Integrado em Informática para o público adolescente e jovem. Nesse processo, as experiências dos Projetos Integradores, no âmbito do curso Proeja em Eletromecânica, foram embrionárias para a introdução do núcleo politécnico comum no campus (SILVA; COSER, 2012). A partir de 2011, com as primeiras turmas do curso de Informática, essas experiências avançaram e foram incorporadas e aprimoradas, ganhando contornos de um núcleo politécnico comum, com as chamadas Oficinas de Integração (Ols), além de outros componentes curriculares, que são ofertados de forma integrada, interdisciplinar e transversal ao longo do currículo integrado desse curso.

Ao analisar o projeto do Curso Técnico Integrado em Informática, de 2010, infere-se a intenção de enfrentar e superar a dualidade entre o ensino propedêutico e profissionalizante, em busca de uma identidade unitária para o EMI, além do

${ }^{13}$ Carreira de Magistério do Ensino Básico, Técnico e Tecnológico. 
compromisso de distanciar essa forma de oferta dos fins do capital e seus interesses imediatos, pragmáticos e utilitários. Na justificativa do referido projeto de curso também se observa o compromisso com a educação politécnica que, por sua vez, é a semente do núcleo politécnico comum ${ }^{14}$.

No que diz respeito às Oficinas de Integração ofertadas nesse curso, evidencia-se um perfil interdisciplinar e integrador, que permite aos educandos perceber a totalidade dos conhecimentos técnicos e gerais. $O$ projeto analisado ressalta que as Ols não devem ser consideradas como disciplina ou unidade curricular isolada, nem ser ministradas por um único professor ou grupo de professores. Pelo contrário, sua construção e execução é responsabilidade de todos os educadores do curso. Conclui-se, a partir dessas características, que as Ols, em parte, materializam o núcleo politécnico comum. Essas oficinas, no Campus Chapecó, foram projetadas em 2010 e concretizadas no Curso Técnico Integrado em Informática, a partir de 2011.A experiência com as Oficinas de Integração no Instituto Federal de Santa Catarina, Câmpus Chapecó, iniciou em fevereiro de 2011, com a primeira turma do curso e foi se ampliando desde então, repetindo-se todos os semestres até hoje, mobilizando distintos grupos de estudantes, educadores e outros profissionais ligados ao Ensino Médio Integrado (SILVA, 2019, p. 24).

Nas Ols desenvolvidas pelo Campus Chapecó, os trabalhos em grupos são estimulados, a fim de despertar no educando o sentimento cooperativo, desenvolvendo a "a auto-organização (autodireção) dos estudantes [...]", que se revela "[...] em três capacidades: a. Habilidade de trabalhar coletivamente. b. Habilidade de trabalhar organizadamente cada tarefa. c. Desenvolvimento da capacidade criativa." (PISTRAK, 2009 apud ARAÚJJ; FRIGOTTO, 2015, p. 74). Ressalta-se que essas oficinas, em conexão com o currículo integrado, buscam a integração e a interdisciplinaridade entre as disciplinas das áreas consideradas gerais, ou da base comum, com as disciplinas consideradas da área técnica, ou específicas.

\footnotetext{
${ }^{14}$ Apesar da busca por uma educação politécnica, é preciso enfatizar que há, no projeto do curso, alguns paradoxos, como, por exemplo, a presença de um componente curricular que trata, ao mesmo tempo, de economia solidária e do empreendedorismo.
} 
Os temas trabalhados durante as Ols dialogam com o eixo tecnológico ao qual o curso está vinculado.

Ao analisar a primeira matriz curricular do curso de Informática, implementada a partir do primeiro semestre de 2011, observa-se a distribuição das unidades curriculares em oito semestres, com carga horária de 3.200h/a, com mínimo de 2.053,33 h/a para a formação geral e 826,67 h/a para a formação técnica, além de 320 h/a para o núcleo politécnico comum. Nota-se também que a oferta do núcleo politécnico comum está representada pelas Ols nos oito semestres/módulos do curso e com carga horária de duas horas aula por semana em cada semestre, além de outras unidades curriculares interdisciplinares, como Tecnologias Assistivas, no módulo VII, com 4 horas-aula semanais e Informática, Empreendedorismo e Economia Solidária, com 4 horas-aula semanais no oitavo módulo.

Grande parte das iniciativas pensadas, em 2010, para o curso de Informática, mantém-se até hoje. A partir de 2017, porém, o projeto do curso sofreu uma reformulação, quando as OIS foram reduzidas de oito para quatro, sendo mantidos os outros componentes curriculares integradores. Apesar disso, a essência politécnica e unitária para o EMI foi mantida.

A trajetória da equipe docente e os desafios da materialidade do núcleo politécnico comum no ensino integrado do IFSC, Campus Chapecó, especialmente no contexto das Ols, são retratados na obra organizada por Silva (2019), intitulada: "Oficinas de Integração: vivências de sala de aula no Ensino Médio Integrado". Além disso, as experiências com ensino integrado, nesse campus, estão descritas também em Pasqualli, Silva e Silva (2019), Silva, Greggio e Agne (2020) e Silva et al. (2016).

No processo de tentativas de avanço nas experiências de ensino integrado, destaca-se que, em 2019, duas portarias normativas foram emitidas pela Direção Geral do Campus Chapecó: a n 26, de 11 de março de 2019 e a n 30, de 11 de março de 2019. Essas portarias tratam da normatização dos GTs, que tiveram como objetivo a reformulação do Curso Técnico de Nível Médio Integrado em Informática e a implementação de um novo curso integrado em Sistemas de Energia Renovável. A partir do acompanhamento e sistematização das reuniões desses dois GTs foram analisados os limites e possibilidades de materialização do núcleo politécnico comum 
na nova organização curricular do EMI desse campus. Salienta-se que esses cursos técnicos integrados pertencem a eixos tecnológicos distintos (Informação e Comunicação e Controle e Processos Industriais, respectivamente).

Com base nas observações e registros feitos durante as reuniões dos GTs, é possível notar que houve intensos debates sobre diferentes assuntos, como as disputas em relação às concepções de Ensino Médio Integrado, os limites e possibilidades das Diretrizes Curriculares Nacionais, o perfil dos jovens que ingressam nos Institutos Federais, a necessidade de diálogo com as demandas sociais do território e as dimensões humana e social das tecnologias. Um dos assuntos debatidos também foi o sistema de oferta semestral e a duração dos cursos técnicos integrados em três ou quatro anos. Para esclarecer essa matéria, foram feitas diversas reuniões ampliadas dos GTs, analisadas publicações acadêmicas sobre o tema e realizada uma assembleia com os estudantes do curso de Informática, que decidiu pela manutenção do curso em quatro anos. É importante pontuar que durante os debates, questões como infraestrutura do campus, carga horária docente, impactos do contraturno na vida acadêmica e familiar do estudante foram amplamente discutidas, bem como os reflexos diretos das mudanças propostas na pesquisa, extensão, monitoria e outros programas institucionais.

A partir do debate realizado e das experiências acumuladas, um dos entendimentos foi de que a manutenção da integração e a maior clareza sobre o curso de Informática deveriam resultar na mudança, também, da área técnica de Informática para Desenvolvimento de Sistemas, preservando as Oficinas de Integração e o componente focado no Empreendedorismo e na Economia Solidária. Entre os motivos para a mudança estão: a carga horária do curso, o foco atual, que já está direcionado para o desenvolvimento de sistemas, entre outras demandas advindas dos profissionais da área técnica. Em função dessa mudança, a nomenclatura utilizada a partir de agora será Curso Técnico Integrado em Desenvolvimento de Sistemas.

Discutiu-se também a mudança do nome do componente Tecnologias Assistivas para Tecnologias para Inclusão. Ao analisar a proposta de uma nova matriz curricular, desenvolvida pelo GT para a reformulação do Curso Técnico Integrado em Desenvolvimento de Sistemas, verificou-se que o núcleo politécnico comum, com 240 
horas, distribuídas em seis componentes curriculares, ficou estruturado da seguinte forma:

Quadro 1. Matriz Curricular das disciplinas que comporão o núcleo politécnico comum do Curso Técnico Integrado em Desenvolvimento de Sistemas do IFSC, Campus Chapecó

\begin{tabular}{l|l|l}
\hline Módulo & Disciplina & Carga horária \\
\hline I & Oficina de Integração I & $40 \mathrm{~h}$ \\
\hline III & Oficina de Integração II & $40 \mathrm{~h}$ \\
\hline V & Oficina de Integração III & $40 \mathrm{~h}$ \\
\hline VI & Empreendedorismo e Economia Solidária & $40 \mathrm{~h}$ \\
\hline VII & Oficina de Integração IV & $40 \mathrm{~h}$ \\
\hline VIII & Tecnologias para Inclusão & $40 \mathrm{~h}$ \\
\hline
\end{tabular}

Para aglutinar o trabalho do núcleo politécnico comum, o curso foi pensado em três etapas: inicial (nos dois primeiros semestres), intermediária (do $3^{\circ}$ ao $6^{\circ}$ semestre) e final (nos dois últimos semestres). Além disso, foram projetados quatro núcleos temáticos: 1) Ciência, Cultura e Sociedade ( $1^{\circ}$ e $2^{\circ}$ semestres); Trabalho, Tecnologia e Poder ( $3^{\circ}$ e $4^{\circ}$ semestres); Sustentabilidade e Ambiente $\left(5^{\circ}\right.$ e $6^{\circ}$ semestres) e Desenvolvimento de Sistemas, Inclusão e Cidadania $\left(7^{\circ}\right.$ e $8^{\circ}$ semestres). Esses núcleos temáticos orientaram a construção das ementas das Ols e demais componentes do núcleo comum.

Quanto à análise da matriz curricular do Curso Técnico Integrado em Sistemas de Energia Renovável, debatida e apresentada pelo GT responsável por sua implementação, percebe-se que houve mais avanços em relação ao núcleo politécnico comum, com a presença de nove componentes curriculares integradores, totalizando 340 horas. Nesse curso, o núcleo politécnico comum ficou assim distribuído:

Quadro 2. Matriz Curricular das disciplinas que comporão o núcleo politécnico comum do Curso Técnico Integrado em Sistemas de Energia Renovável - IFSC, Campus Chapecó

\begin{tabular}{l|l|l}
\hline Módulo & Disciplina & Carga horária \\
\hline
\end{tabular}




\begin{tabular}{l|l|l}
\hline I & Introdução ao Estudo das Energias & $40 \mathrm{~h}$ \\
\hline I & Oficina de Integração I & $40 \mathrm{~h}$ \\
\hline II & Energias Renováveis & $40 \mathrm{~h}$ \\
\hline III & Oficina de Integração II & $40 \mathrm{~h}$ \\
\hline IV & Tópicos Especiais em Língua Espanhola & $20 \mathrm{~h}$ \\
\hline V & Oficina de Integração III & $40 \mathrm{~h}$ \\
\hline VI & Empreendedorismo e Economia Solidária & $40 \mathrm{~h}$ \\
\hline VII & Oficina de Integração IV & $40 \mathrm{~h}$ \\
\hline VIII & $\begin{array}{l}\text { Tecnologias Sociais e Desenvolvimento Regional } \\
\text { Sustentável }\end{array}$ & $40 \mathrm{~h}$ \\
\hline & Fonte: GT para implantação do curso de Sistemas de Energia Renovável (2019).
\end{tabular}

Fonte: GT para implantação do curso de Sistemas de Energia Renovável (2019).

Para esse curso, também foram definidas as três etapas descritas acima e os quatro núcleos temáticos. Os três primeiros núcleos temáticos foram os mesmos e com igual distribuição do curso de Desenvolvimento de Sistemas. Porém, o último foi denominado de Aplicações aos Sistemas de Energias Renováveis, visando a uma maior aproximação com a realidade local. Observa-se, ainda, que há componentes do núcleo comum em todos os oito semestres, para o curso de Sistemas de Energia Renovável.

Percebe-se que a organização da matriz curricular de ambos os cursos possibilita a oferta de núcleos politécnicos ao longo dos itinerários formativos que, de algum modo, podem permitir uma aproximação entre as matrizes curriculares dos cursos integrados, além de possibilitar um maior intercâmbio de experiências entre docentes e discentes dos cursos técnicos integrados, mesmo que de eixos tecnológicos distintos.

A busca por um exercício de aproximação entre núcleos politécnicos comuns de eixos tecnológicos distintos: Informação e Comunicação (técnico em Informática/Desenvolvimento de Sistemas) e Controle e Processos Industriais (técnico em Sistemas de Energia Renovável), levaram os GTs a pensar formas de aproximação entre os dois cursos. Nessa direção, foram discutidas possibilidades de flexibilização ${ }^{15}$ curricular, que aproximassem os cursos, mas que garantissem, a

${ }^{15}$ A flexibilização curricular defendida por esta pesquisa trata de uma maior aproximação curricular entre os cursos do Ensino Médio Integrado, a partir do núcleo politécnico comum ou outra unidade curricular interdisciplinar, Revista Labor, V 1, N. 24 DOI: https://doi.org/10.29148/revista\%20labor.v1123.44085 http://www.periodicos.ufc.br/labor/index ISBN: $1983-5000$ 
ambos, sua identidade. Assim, as Ols e outros componentes curriculares definidos para o núcleo politécnico comum ganharam grande relevância nos debates realizados, haja vista serem ações pedagógicas que possibilitam um horizonte integrado, interdisciplinar e dialógico do conhecimento, bem como um caminho, dentro dos itinerários formativos, que consolide uma formação humana mais alargada. Busca-se, com isso, uma formação integral, com foco nos problemas da realidade que o aluno está inserido e na sua resolução. Entretanto, o grupo foi além das Ols, propondo outros seis componentes curriculares para o núcleo politécnico comum.

Segundo os relatos dos membros dos GTs e demais professores, a experiência nas Ols e outros componentes curriculares com características interdisciplinares permitiu a compreensão e efetivação do núcleo politécnico comum. Contudo, com base nas informações registradas nas reuniões, observou-se que os limites para a materialização do núcleo politécnico comum ainda é uma questão desafiadora para todos os envolvidos; por isso, os debates acerca do tema não foram isentos de embates e tensões. Porém, predominou, no entendimento dos GTs analisados, a defesa de uma formação ampliada e integral.

\section{Considerações Finais}

É consenso entre diferentes pesquisadores do campo da Educação, que os processos educativos em Educação Profissional e Tecnológica no Brasil, ao longo da sua história, têm se mostrado um movimento contínuo e permanente de luta, seja para a manutenção da ordem vigente pelos atores hegemônicos, seja pela luta contrahegemônica daqueles que acreditam numa educação para além do capital, pois a educação, em todos os seus níveis e modalidades, deve ser pensada num todo integrado e dialeticamente construído com seus sujeitos, refletindo sempre a materialidade histórica.

Visando materializar a perspectiva de formação integral dos trabalhadores, a síntese realizada a partir do acompanhamento dos GTs aqui mencionados mostra 
um esforço coletivo de reflexão sobre a prática, tomando as experiências acumuladas como ponto de partida para o debate e a proposição de avanços no EMI. Tendo como horizonte um olhar sobre as particularidades, mas, principalmente, sobre a totalidade dos processos formativos, professores, estudantes e comunidade acadêmica em geral, conseguiram dar materialidade ao que, para muitos, permanece apenas como um conceito e uma utopia a ser alcançada: o núcleo politécnico comum. Ao se disporem a esse desafio, os envolvidos avançaram também em relação à dimensão metodológica dessa proposição e à própria efetivação do conceito de politécnica.

A práxis pedagógica politécnica é uma tarefa cara aos educadores que desafiam a formação profissional imersa numa lógica mercadológica de uma sociedade capitalista periférica. Deve-se buscar sempre, como horizonte a ser seguido, itinerários formativos que conduzam a uma Educação Profissional e Tecnológica amparada no trabalho como princípio educativo, bem como na construção coletiva e participativa de um núcleo politécnico comum, que seja capaz de dialogar com professores e alunos de diferentes eixos tecnológicos, tendo como ponto de chegada a formação humana integral e a consciência de pertencimento à classe trabalhadora.

Diante do todo observado e registrado, conclui-se que as discussões para reformulação do Curso Técnico Integrado em Informática, que resultaram no curso de Desenvolvimento de Sistemas, assim como a implantação do Curso Técnico Integrado em Sistemas de Energia Renovável do IFSC, Campus Chapecó, constituíram-se em momentos ímpares para a concretização de avanços em relação ao núcleo politécnico comum no EMI. Cabe sublinhar os esforços que os GTs e os docentes, de maneira geral, empreenderam na busca por uma integração curricular a partir de um núcleo politécnico comum dialógico, capaz de aproximar cursos de eixos tecnológicos distintos, mas mantendo sua identidade. Nessa perspectiva, observou-se um amplo debate democrático e coletivo que, apesar da heterogeneidade de formação do grupo, aproximou os diferentes sujeitos envolvidos, servindo como espaço de construção de consensos e de autoformação pedagógica e política.

Por fim, no exercício da práxis pedagógica, em breve, poderá mostrar-se possível ver, com mais precisão, a integração curricular nos cursos analisados. A 
resposta para essa inquietação tende a ser dada a partir de 2021 , quando os novos projetos deverão ser implantados e a utopia de uma forma contra-hegemônica explicitar-se-á nas práticas cotidianas do EMI.

\section{Referências}

ANTUNES, C. A educação em Mészáros: trabalho, alienação e emancipação. Campinas: Autores Associados, 2012. 130 p.

ARAÚJO, A. C.; SILVA, C. N. N. (Orgs.). Ensino Médio Integrado no Brasil: fundamentos, práticas e desafios. Ed. IFB, 2017. Disponível em: http://www.anped.org.br/sites/default/files/images/livro completo ensino medio inte grado - 1310 2017.pdf. Acesso em: 14 jun. 2020.

ARAUJO, R. M. de; FRIGOTTO, G. Práticas pedagógicas e ensino integrado. Revista Educação em Questão, v. 52, n. 38, p. 61-80, 2015. Disponível em: https://periodicos.ufrn.br/educacaoemquestao/article/view/7956/5723. Acesso em: 13 jun. 2020.

BRASIL. Decreto 2.208, 1997. Regulamenta o $\S 2^{\circ}$ do art. 36 e os arts. 39 a 42 da Lei $n^{\circ}$ 9.394, de 20 de dezembro de 1996, que estabelece as diretrizes e bases da educação nacional. Disponível em: http://www.planalto.gov.br/ccivil 03/decreto/D2208.htm. Acesso em: 08 jun. 2020.

BRASIL. Decreto 5.154, 2004. Regulamenta o $\S 2^{\circ}$ do art. 36 e os arts. 39 a 41 da Lei $n^{\circ}$ 9.394, de 20 de dezembro de 1996, que estabelece as diretrizes e bases da educação nacional, e dá outras providências. Disponível em: http://www.planalto.gov.br/ccivil 03/ ato2004-2006/2004/decreto/d5154.htm. Acesso em: 08 jun. 2020.

BRASIL. Lei 11.892, de 29 de dezembro de 2008. Institui a Rede Federal de Educação Profissional, Científica e Tecnológica, cria os Institutos Federais de Educação, Ciência e Tecnologia. Disponível em: http://www.planalto.gov.br/ccivil 03/ Ato2007-2010/2008/Lei/L11892.htm. Acesso em: 05 jun. 2020.

BRASIL. Lei 13.415, de 16 de fevereiro de 2017. Altera as Leis $\mathrm{n}^{\circ} 9.394$, de 20 de dezembro de 1996, que estabelece as diretrizes e bases da educação nacional, e 11.494, de 20 de junho 2007. Disponível em: http://www.planalto.gov.br/ccivil 03/ Ato2015-2018/2017/Lei/L13415.htm. Acesso em: 05 jun. 2020.

BRASIL. Ministério Educação. Secretaria de Educação Profissional e Tecnológica. Catálogo Nacional de Cursos Técnicos. 3. ed. Brasília: Ministério da Educação, 2016. Disponível em: http://portal.mec.gov.br/docman/novembro-2017-pdf/77451- 
cnct-3a-edicao-pdf-1/file. Acesso em: 03 jun. 2020.

BRASIL. Parecer CNE/CEB n 11/2008. Proposta de instituição do Catálogo Nacional de Cursos Técnicos de Nível Médio. Disponível em: http://portal.mec.gov.br/setec/arquivos/pdf/pceb011 08.pdf. Acesso em: 14 jun. 2020.

BRASIL. Resolução CNE/CEB n 6, de 20 de setembro de /2012. Define diretrizes curriculares nacionais para a educação profissional técnica de nível médio. Disponível em:

http://portal.mec.gov.br/index.php?option=com docman\&view=download\&alias=1166 3-rceb006-12-pdf\&category slug=setembro-2012-pdf\&ltemid=30192. Acesso em: 26 jun. 2020.

CALDEIRA, A. M. S.; ZAIDAN, S. Práxis pedagógica: um desafio cotidiano. Paidéia, Belo Horizonte, v. 10, n. 14, p. 15-32, 2013. Disponível em: http://www.fumec.br/revistas/paideia/article/view/2374/1430. Acesso em: 04 ago. 2020.

CIAVATTA, M. A formação integrada e o trabalho como lugares de memória e identidade. In.: FRIGOTTO, G.; CIAVATTA M.; RAMOS, M. (Orgs.). Ensino Médio Integrado: concepções e contradições. 3. ed. São Paulo: Cortez, 2012. 175 p.

CIAVATTA, Maria. O trabalho como princípio educativo. In: Dicionário da Educação Profissional em Saúde. Rio de Janeiro: Fiocruz, 2009. Disponível em: http://www.sites.epsjv.fiocruz.br/dicionario/verbetes/trapriedu.html. Acesso em: $1^{\circ}$ ago. 2020.

CIAVATTA, M.; RAMOS, M. Ensino médio e educação profissional: dualidade e fragmentação. Revista Retrato da Escola, v. 5, n. 8, p. 27-41, 2011. Disponível em: http://retratosdaescola.emnuvens.com.br/rde/article/viewFile/45/42. Acesso em: 17 jun. 2020.

FRIGOTTO, G.; CIAVATTA, M.; RAMOS, M. A gênese do decreto n. 5.154/2004: um debate no contexto controverso da democracia restrita. Trabalhos necessários. Ano 3 , n. $3, \quad 2005 . \quad$ p. $1-26$. Disponível em: http://forumeja.org.br/pf/sites/forumeja.org.br.pf/files/CIAVATTAFRIGOTTORAMOS. pdf. Acesso em: 10 jun. 2020.

GADIN, D. A prática do planejamento participativo. 15. ed. Petrópolis: Vozes, 2008. $182 \mathrm{p}$.

GALLO, S. Politecnia e educação: a contribuição anarquista. Revista Pro-Posições, v. $4, \quad$ n. $3, \quad$ nov. 1993. Disponível em: https://periodicos.sbu.unicamp.br/ojs/index.php/proposic/article/view/8644347/11765. Acesso em: 03 set. 2020. 
GRAMSCI, A. Os intelectuais e a organização da cultura. 4. ed. Rio de Janeiro: Civilização Brasileira, 1982. 244 p.

INSTITUTO FEDERAL DE SANTA CATARINA. Portaria da $\mathrm{n}^{\circ} 26$, de 11 de março de 2019. Direção-Geral do Câmpus Chapecó, 2019.

INSTITUTO FEDERAL DE SANTA CATARINA. Portaria da $\mathrm{n}^{\circ} 30$, de 11 de março de 2019. Direção-Geral do Câmpus Chapecó, 2019a.

MACHADO, L. R. S. Organização da Educação Profissional e Tecnológica por Eixos Tecnológicos. Linhas Críticas, v. 16, n. 30, p. 89-108, 2010. Disponível em: http://www.redalyc.org/pdf/1935/193514392004.pdf. Acesso em: 11 jun. 2020.

MARX, K. O capital: crítica da economia política. Livro I: o processo de produção do capital. 2. ed. São Paulo: Boitempo, 2017. 894 p.

MOURA, D. H. Educação básica e educação profissional e tecnológica: dualidade histórica e perspectivas de integração. Revista Holos, v. 2, ano 23, p. 4-30, 2007. Disponível em: http://www2.ifrn.edu.br/ojs/index.php/HOLOS/article/viewFile/11/110. Acesso em: 17 jun. 2020.

MOURA, D. H.; LIMA FILHO, D. L.; SILVA, M. R. Politecnia e formação integrada: confrontos conceituais, projetos políticos e contradições históricas da educação brasileira. Revista Brasileira de Educação, v. 20, n. 63, p. 1057-1080, 2015. Disponível em: http://www.scielo.br/pdf/rbedu/v20n63/1413-2478-rbedu-20-631057.pdf. Acesso em: 07 jun. 2020.

NOSELLA, P. Trabalho e perspectivas de formação dos trabalhadores: para além da formação politécnica. Revista Brasileira de Educação. v. 12, n. 34, p. 137-151, 2007. Disponível em: https://www.scielo.br/pdf/rbedu/v12n34/a11v1234.pdf. Acesso em: 04 set. 2020.

PASQUALLI, R.; SILVA, V.; SILVA, A. L. Limites e potencialidades de materialização do currículo integrado: uma análise dos planos de ensino e diários de Classe. Revista Contexto e Educação, Editora Unijuí, Ano 34, n. 109, set./dez., p. 104-120, 2019. Disponível em: https://www.revistas.unijui.edu.br/index.php/contextoeducacao/article/view/7631. Acesso em: $1^{\circ}$ ago. 2020.

PISTRAK, M. M. Fundamentos da escola do Trabalho: uma pedagogia social. São Paulo: Expressão Popular, 2015. 256 p.

RAMOS, M. Concepção de Ensino Médio Integrado. Secretaria de Educação do Estado do Paraná, 2008. p. 1-30. Disponível em: https://tecnicadmiwj.files.wordpress.com/2008/09/texto-concepcao-do-ensino-mediointegrado-marise-ramos1.pdf. Acesso em: 11 jun. 2020. 
RAMOS, M. Ensino Médio Integrado: ciência, trabalho e cultura na relação entre educação profissional e educação básica. In.: MOLL, J. Educação Profissional e tecnológica no Brasil contemporâneo: desafios, tensões e possibilidades. Porto Alegre: Artmed, 2010. 312 p.

SÁNCHEZ VÁZQUEZ, A. Filosofia da práxis. 2. ed. Rio de Janeiro: Paz e Terra, 1977. $454 \mathrm{p}$.

SAVIANI, D. O choque teórico da politecnia. Trabalho, Educação e Saúde, v. 1, n. 1, p. 131-152, 2003. Disponível em: https://www.scielo.br/pdf/tes/v1n1/10.pdf. Acesso em: 14 jun. 2020.

SAVIANI, D. Trabalho e Educação: fundamentos ontológicos e históricos. Revista Brasileira de Educação, v. 12, n. 34, p. 152-184, 2007. Disponível em: http://www.scielo.br/pdf/rbedu/v12n34/a12v1234.pdf. Acesso em: 2 jun. 2020.

SILVA, A. L. Currículo integrado. Florianópolis: IFSC, 2014. E-book. 97p. Disponível em: https://educapes.capes.gov.br/bitstream/capes/204363/2/Esp\%20Proeja\%20\%20Curr\%C3\%ADculo\%20Integrado\%20-\%20MIOLO.pdf. Acesso em: 06 jun. 2020.

SILVA, A. L. Oficinas de Integração: uma história feita a várias mãos. In: SILVA, A. L (Org.) Oficinas de Integração: vivências de sala de aula no ensino médio integrado. Curitiba: CRV, 2019. 198p.

SILVA, A. L.; COSER, J. A experiência do Projeto Integrador I no curso de Proeja em Eletromecânica do IF-SC Câmpus Chapecó. Revista Técnico-Científica (RTC), Florianópolis, v. 1, n. 3 , p. 9-19, 2012. Disponível em: https://periodicos.ifsc.edu.br/index.php/rtc/article/view/932/614. Acesso em: 06 jun. 2020.

SILVA, A. L.; PASQUALLI, R.; GREGGIO, S.; AGNE, S. (Org.). O currículo integrado no cotidiano da sala de aula. Florianópolis: IFSC, 2016. 168p.

SILVA, A. L.; GREGGIO, S.; AGNE, S. A integração curricular na percepção dos estudantes de três câmpus do Instituto Federal de Santa Catarina. Revista Brasileira de Educação Profissional e Tecnológica, Natal, v. 1, n. 18, p. 1-16, 2020. Disponível em: http://www2.ifrn.edu.br/ojs/index.php/RBEPT/article/view/7929. Acesso em: $1^{\circ}$ ago. 2020.

SILVA, L. T.; NOSELLA, P. A "cultura extrema" enquanto estratégia de hegemonia: uma análise a partir dos escritos de Antônio Gramsci. Revista Labor, Fortaleza/CE, n. 22, v. 1, jul./dez., p. 19-31, 2019. Disponível em: http://www.periodicos.ufc.br/labor/article/view/42630/100355. Acesso em: 04 set. 2020.

SOBRINHO, S. C. Diretrizes institucionais e a perspectiva da integração curricular no IF Farroupilha. In: ARAÚJO, Adilson Cesar; SILVA, Claudio Nei Nascimento (Orgs.). 
Ensino Médio Integrado no Brasil: fundamentos, práticas e desafios. Ed. IFB, 2017. Disponível em: http://www.anped.org.br/sites/default/files/images/livro completo ensino medio inte grado - 1310 2017.pdf. Acesso em: 04 jun. 2020.

SOUSA JUNIOR, J. OMNILATERALIDADE. In: Dicionário da Educação Profissional em Saúde. Rio de Janeiro: Fiocruz, 2009. Disponível em: http://www.sites.epsjv.fiocruz.br/dicionario/index.html. Acesso em: 04 set. 2020.

THIESEN, J. da S.. Currículo interdisciplinar: contradições, limites e possibilidades. Revista Perspectiva, v. 31, n. 2, p. 591-614, 2013. Disponível em: https://periodicos.ufsc.br/index.php/perspectiva/article/view/2175795X.2013v31n2p591. Acesso em: 24 set. 2018.

VASCONCELLOS, C. Planejamento: projeto de ensino-aprendizagem e projeto político-pedagógico. 19. ed. São Paulo: Libertad, 2009. 205p.

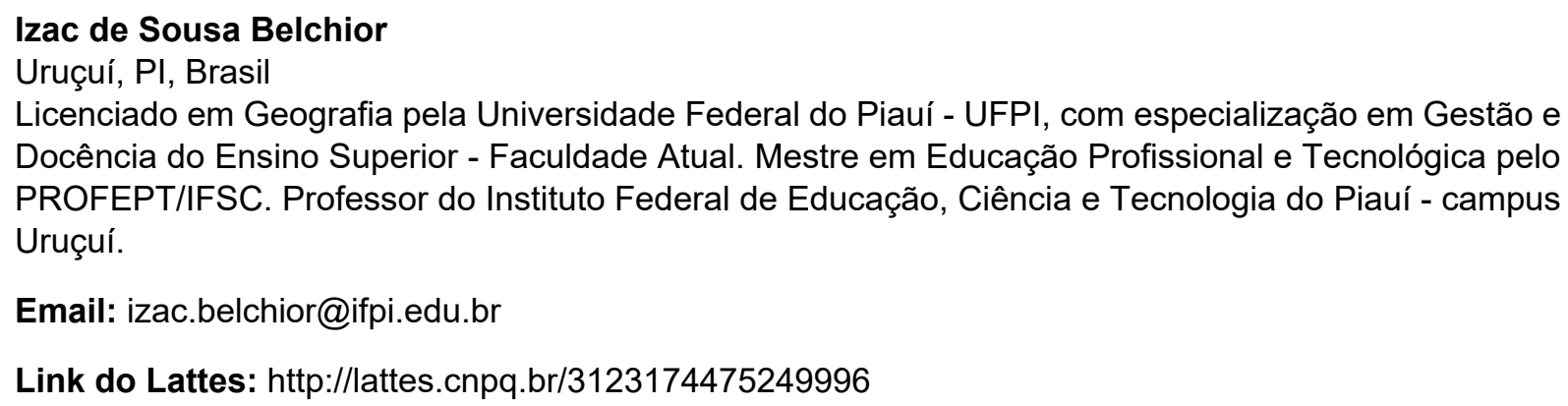

\section{Adriano Larentes da Silva}

Chapecó, SC, Brasil

Pós-doutor em Educação pela Universidade Nacional Autônoma do México e em Políticas Públicas e Formação Humana pela Universidade do Estado do Rio de Janeiro. Doutor em História pela Universidade Federal de Santa Catarina e professor do Instituto Federal de Educação de Santa Catarina, Campus Chapecó. É professor do mestrado PROFEPT/IFSC.

Email: adriano.larentes@gmail.com

Link do Lattes: http://lattes.cnpq.br/4667474166242258

Recebimento: $14 / 07 / 2020$

Aprovação: 16/09/2020 
Revista Labor

Programa de Pós-graduação em Educação, Universidade Federal do Ceará

Fortaleza-CE-Brasil

\section{Q.Code}

\section{Editores-Responsáveis}

Prof. Dr. Enéas de Araújo Arrais Neto, Universidade Federal do Ceará - UFC, Brasil

Prof. Dr. Arno Münster, Universidade de Amiens - Paris, França 